\title{
SENI DAN BUDAYA SEBAGAI RUANG KETIGA DAN WADAH BEREKSPRESI DI PONDOK KELAPA: RUANG EKSPRESI
}

\author{
Wewin Febriana Dewi ${ }^{1)}$, Maria Veronica Gandha ${ }^{2)}$ \\ 1)Program Studi S1 Arsitektur, Fakultas Teknik, Universitas Tarumanagara, wewinfebriana@gmail.com \\ ${ }^{2)}$ Program Studi S1 Arsitektur, Fakultas Teknik, Universitas Tarumanagara, mariag@ft.untar.ac.id
}

Masuk: 13-07-2020, revisi: 01-08-2020, diterima untuk diterbitkan: 24-09-2020

\begin{abstract}
Abstrak
Pondok Kelapa adalah Kelurahan yang berada di tepi Jakarta Timur dan didominasi oleh pemukiman, menurut data dari Badan Kependudukan dan Keluarga Berencana Nasional (disingkat BKKBN) ${ }^{1}$ dominasi umur di pondok kelapa berkisar 6 tahun hingga 22 tahun, umur dimana lebih suka berkumpul bertukar informasi dengan teman seusianya. Ruang ketiga adalah ruang untuk manusia bertemu dan bertukar informasi, penilitian ini menggunakan kriteria dari buku Ray Olderburg tahun 1999 yang berjudul The Great Good Place. Ruang ketiga bukan rumah dan bukan tempat berkerja, Ruang Ketiga sering dijadikan remaja untuk berkumpul. Ruang Ketiga memiliki peran penting untuk manusia, maka dari itu semua manusia berhak memilikinya di lingkungan la tinggal. Kurangnya ruang ketiga di pondok kelapa menyebabkan warganya pergi ke pusat kota dimana ruang ketiga lebih baik dan hal ini menyebabkan kemacetan di akhir minggu. Tujuan dari penilitian ini adalah menerapkan kriteria ruang ketiga pada bangunan seni dan budaya sebagai wadah positif juga wadah komunitas bagi lingkungan.
\end{abstract}

\section{Kata kunci: Ekspresi; Ruang Ketiga; Seni dan Budaya}

\begin{abstract}
Pondok Kelapa is an area located on the edge of East Jakarta and is dominated by settlements, according to data from BKKBN the dominance of age in Pondok Kelapa ranges from 6 years old to 22 years old, the age at which people prefer to gather to exchange information with their friends. The third place is a space for humans to meet and exchange information, this research of Third Place uses criteria from The Great Good Place, a book by Ray Oldenburg(1999). It is not home and it is not a place to work, the third place is often used as teenagers to gather. The third place has an important role for humans, therefore all humans have the right to have it in the environment they live. The lack of a third place in the Pondok Kelapa causes its citizens to go downtown where the third room is better and this causes traffics on weekends. The purpose of this research is to apply the criteria of the third place in the arts and culture building as a positive container as well as a community forum for the environment.
\end{abstract}

Keywords: Art and Culture; Expression; Third place

\footnotetext{
${ }^{1}$ BKKBN, “Kampung KB Kelurahan Pondok Kelapa” (http://kampungkb.bkkbn.go.id/profile/2981, accessed on June 18, 2020)
} 


\section{PENDAHULUAN}

\section{Latar Belakang}

Menurut Oldenburg, 1999, dalam bukunya yang berjudul The Great Good Place, tidak adanya ruang untuk bertemu atau sekedar bersantai di luar rumah atau tempat kerja dapat membuat seseorang merasa terisolasi dan bosan, sehingga kebutuhan ruang ketiga untuk bertemu dan berkumpul menjadi penting. Third place adalah ruang dimana bukan rumah dan kantor dimana tempat yang sangat diperlukan oleh manusia dan keberadaannya di Jakarta sudah dikuasai untuk kepentingan bisnis seperti café atau mall . Salah satunya Pondok Kelapa, third place hanya ada café, yang mana harus membeli makanan atau minuman baru dapat duduk dan bertemu, dan juga dari isu yang telah diteliti, Pondok Kelapa memiliki isu yang tidak terlalu terkenal di Jakarta tetapi diketahui oleh warga Pondok Kelapa itu sendiri, yaitu penjualan narkoba, yang dilakukan sembunyi-sembunyi kepada mahasiswa dan remaja. Mengekspresikan emosi dan menuangkan isi hati yang dirasakan disebut juga 'kataris'. Kataris ada yang baik ada juga yang tidak baik, yang tidak baik antara lain adalah: menggunakan narkoba, menangis berhari-hari, berkata kasar, mengendarai kendaraan dengan kecepatan tinggi, dan lainnya. Kataris yang baik antara lain: mengunjungi suatu tempat yang menarik, melukis, menulis puisi, menari, olahraga, mewarnai, jalan-jalan, bermain live music, mendengarkan musik dan lainnya ${ }^{3}$. Maka dari itu dibutuhkan sebuah wadah fisik sebagai tempat untuk warga sekitar berkumpul, bertemu dan bersantai yang tujuannya untuk seni dan budaya.

\section{Rumusan Permasalahan}

Pondok Kelapa adalah kelurahan yang berada di Jakarta Timur. Ruang ketiga yang terdapat di Pondok Kelapa didominasi café dan restoran, yang sifatnya tidak netral, salah satu syarat utama ruang ketiga seharusnya netral, sehingga kalangan manapun dapat masuk dan menggunakan Ruang Ketiga tanpa harus membayar apapun.

\section{Tujuan}

Kesehatan mental sangatlah penting sama seperti kesehatan fisik, tapi di Indonesia kesehatan mental masih dianggap tabu. Saat seseorang tidak tahu bagaimana cara menyalurkan emosinya mereka dapat menjadi stress atau bahkan beralih ke pelarian yang negatif seperti narkoba atau menyakiti diri sendiri. Salah satu pelarian sebagai penyaluran emosi yang positif salah satunya melalui seni. Seni sebagai pelarian seseorang saat merasa sedih. Menurut tim penilitian University of Western Australia, seni dapat memperbaiki kesehatan mental. Peniliti melakukan penelitian terhadap 702 orang dewasa dimana 100 orang yang menghabiskan waktu lebih dari 100 jam dalam kesenian memeiliki kesehatan mental yang lebih baik ketimbang mereka yang tidak. Menurut Dr. Christina Davies, melakukan aktivitas kesenian dapat meingkatkan rasa bahagia, rasa percaya diri, penilaian diri dan mengurangi stress serta isolasi sosial ${ }^{4}$. Memberikan wadah baru untuk Ruang Ketiga bagi komunitas setempat sebagai bangunan yang dapat dikunjungi oleh siapapun dari kalangan manapun untuk sekedar bertemu dan bersantai hingga mendengarkan live music di Ruang Ekspresi sehingga tujuannya adalah untuk meningkatkan kualitas hidup warga Pondok Kelapa.

\section{KAJIAN LITERATUR}

Menurut Frank Lloyd Wright (1867-1959), sebuah kota memerlukan sebuah perencanaan untuk mewujudkan dunia modern, dimana dapat meningkatkan kualitas hidup warganya dalam sekala besar, sehingga tercipta "healthy social communities". Tanpa adanya ruang

\footnotetext{
${ }^{2}$ Ray Oldenburg., The Great Good Place (New York: Da Capo Press, 1999)

${ }^{2}$ Ray Oldenburg., The Great Good Place (New York: Da Capo Press, 1999)

3 Drzikia A Primala, "Katarsis: Cara Mengungkap Emosi" (www.pijarpsikologi.org, accessed on June 18, 2020)

${ }^{4}$ Judith Mackrell, "Dance" (https://www.britannica.com/art/dance, accessed on June 18, 2020)
} 
publik untuk berkumpul masyarakat dapat merasa terkurung, anak-anak tumbuh tanpa merasakan hubungan sosial dan tak dapat belajar tentang tanggung jawab dilingkungan selain rumah ${ }^{5}$. Ruang Ketiga adalah ruang publik yang tidak dimiiki oleh komunitas tertentu, informal dan tempat berkumpulnya individu selain di rumah maupun di tempat kerja, masyarakat berkumpul dan bertukar informasi satu dengan yang lain, sehingga dapat pula meningkatkan kesehatan jasmani dan rohani. Ruang Ketiga bersifat netral, simple dan flesibel. Berikut ini adalah beberapa kriteria Ruang Ketiga menurut Ray Oldenburg ${ }^{1}$ :

a. Netral

Ruang yang tidak terlibat oleh apapun, dari politik sampai komunitas tertentu, ruang dengan sifat netral.

b. Leveler

Tidak memperdulikan status ekonomi ataupun sosial. Siapapun dapat berpartisipasi di dalam Third Place.

c. Conversation is the main activity

Aktivitas yang paling mendominasi di ruang ketiga adalah mengobrol dan bertukar informasi.

d. Accessible

Mudah diakses darimana saja, tidak memiliki boundaries.

e. Regulars

Dapat digunakan oleh siapapun karena bentuk atau tampilannya yang tidak extravagant, something usual and welcoming to everybody.

f. Physically plain and unpretentious

Sederhana dan dapat diterima oleh semua kalangan.

g. Dominan mood: Playful

Ruang dimana mereka tidak dirumah tapi merasa seperti dirumah, memiliki suasana hangat dan nyaman.

Tak jauh berbeda dengan Ray Oldenburg, menurut Agustinus Susanto dalam kuliah umumnya, tentang Ruang Ketiga pada 16 Januari 2020 di Universitas Tarumanagara, ada beberapa kriteria ruang ketiga yaitu; bersifat terbuka, sehingga siapapun dapat masuk, dapat bertukar informasi dan mudah dijangkau; dan fleksible dimana dapat menjadi tempat dengan berbagai tujuan dan dapat dengan mudah diterima oleh masyarakat sekitar dimana bangunan tersebut berada.

\section{METODE}

Metode yang digunakan bersifat analisa kualitatif, yaitu analisa data-data yang diperlukan untuk dikembangkan dan menemukan konsep yang berhubungan dengan objek perancangan selanjutnya.

\section{Ruang Lingkup Penelitian}

Dalam perancangan ini mencakup ruang lingkup yang tidak besar, hanya sebesar kelurahan yaitu Kelurahan Pondok Kelapa, Duren Sawit, Jakarta Timur. Maka ruang lingkup dibatasi pada masalah sebagai berikut:

a. Karakteristik lokasi, mengenai karakter lokasi di Kelurahan Pondok Kelapa dengan cara melihat data-data yang diperlukan untuk perancangan seperti data penduduk, mulai dari umur hingga perkerjaan, data perkerjaan yang digeluti oleh penduduk.

b. Mencari solusi dan penyelesaian tentang apa yang dibutuhkan oleh warga Pondok Kelapa dari karakteristik yang muncul dari data yang ada karena tujuan dari proyek ini adalah merancang sebuah 'neighborhood facility'

c. Dokumentasi di daerah Pondok Kelapa

\footnotetext{
5 Joanne Dolley - Caryl Bosman, Rethinking Third Place (Cheltenham, UK: Edward Elgar Publishing Limited, 2019), 4-11
} 
Dari batasan-batasan yang sudah ditentukan sebelum merancang, diharapkan proses merancang tidak lebih besar dari Kelurahan Pondok Kelapa dan lebih berfokus ke penduduk di daerah tersebut dan diharapkan dapat menjawab permasalahan yang ada pada saat ini.

\section{Pengumpulan data}

\section{Teknik pengumpulan data}

Agar dapat memperoleh data-data yang valid perlu pengumpulan data yang benar dan banyak cara, maka dari itu menggunakan metode sebagai berikut:

a. Observasi

Metode observasi yaitu mengamati daerah yang sedang diselediki dan didapat data-data.

Mulai dari observasi penduduk, karakter area tersebut, berkeliling di daerah tersebut dan juga mencatat data yang ada.

b. Dokumentasi

Penulis mendapat data dari buku, internet, peraturan yang berlaku, catatan pribadi dan sebagainya.

c. Studi litelatur

Melakukan studi dari bangunan-bangunan yang memiliki program yang sama sehingga memiliki gambaran tentang Ruang Ketiga dan dapat diterapkan pada proyek.

\section{Analisis data}

Dalam proses analisis data penulis melakukan analisis dari data yang sudah dikumpulkan. Dari analisis data ini penulis dapat menyampaikan dan menyimpulkan fenomena yang terjadi di wilayah Pondok Kelapa secara detail dan rinci sehingga proses menuju perancangan lebih mudah dan jelas.

\section{Analisis pengguna}

Proses ini dilakukan dengan cara melakukan survey pada lingkungan tapak berada, sehingga diketahui pengguna di Ruang Ekspresi serta aktifitas apa saja yang mungkin terjadi didalamnya.

\section{DISKUSI DAN HASIL}

\section{Penjelasan proyek: Ruang Ekspresi}

Kawasan yang dipilih berada di Jakarta Timur tepatnya Kelurahan Pondok Kelapa, Kec. Duren Sawit. Kelurahan ini bersebelahan langsung dengan Kota Bekasi. Luas: 5 ha; Jumlah jiwa: 86.075 (data 2016)

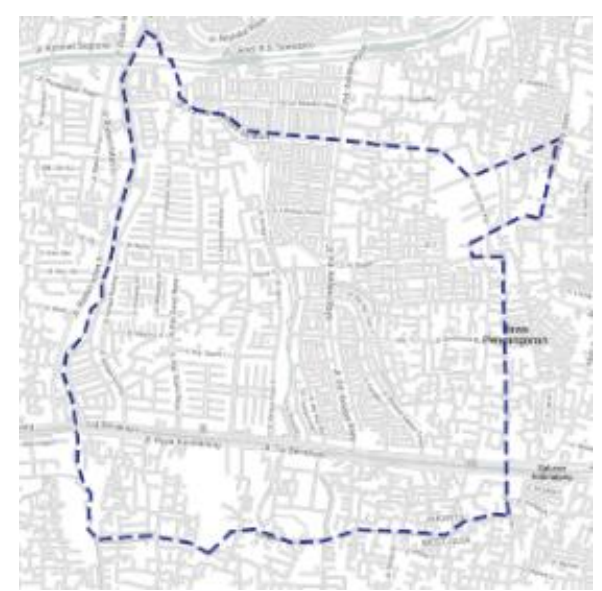

Gambar 1. Peta Kelurahan Pondok Kelapa

Sumber : Penulis, 2020 


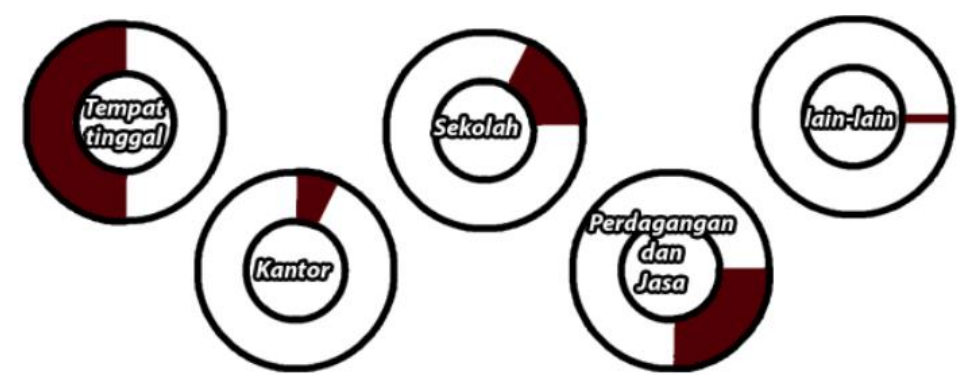

Gambar 2. Diagram fungsi lahan di Pondok Kelapa Sumber : Penulis, 2020

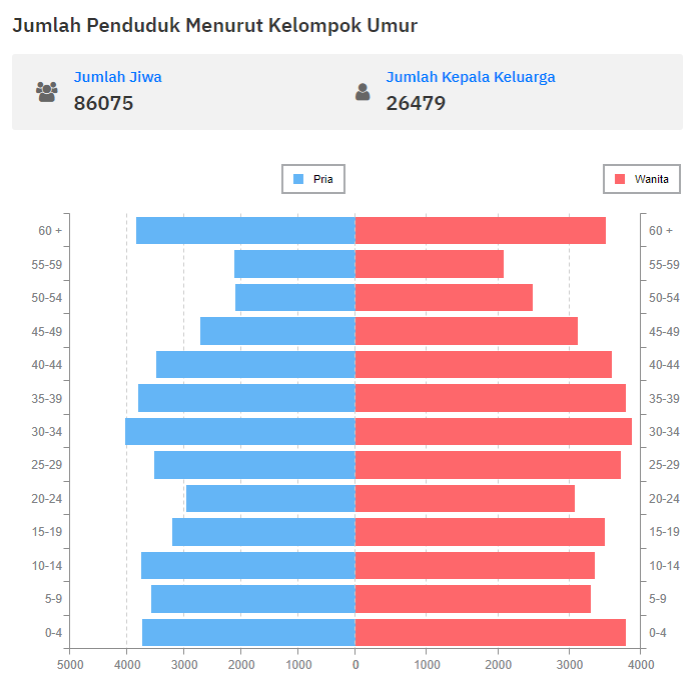

Gambar 3. Diagram jumlah penduduk menurut kelompok umur Sumber : Penulis, 2020

Pondok Kelapa didominasi oleh rumah tinggal dan penduduk paling banyak adalah pelajar, maka dari itu fokusnya adalah wadah yang dapat dikunjungi oleh remaja tapi tidak menutup kemungkinan siapapun dapat datang. Tujuan dari proyek ini adalah memberi wadah untuk seni dan budaya bagi warga Pondok Kelapa. Data tapak adalah Luas tapak: $50 \times 50=2500 \mathrm{~m}^{2}$; Fungsi lahan: Zona perkantoran, perdagangan dan asing; KDB: $50=1250 \mathrm{~m}^{2} ; \mathrm{KLB}: 2=$ $2500 \mathrm{~m}^{2}$; KDH: $750 \mathrm{~m}^{2}$.

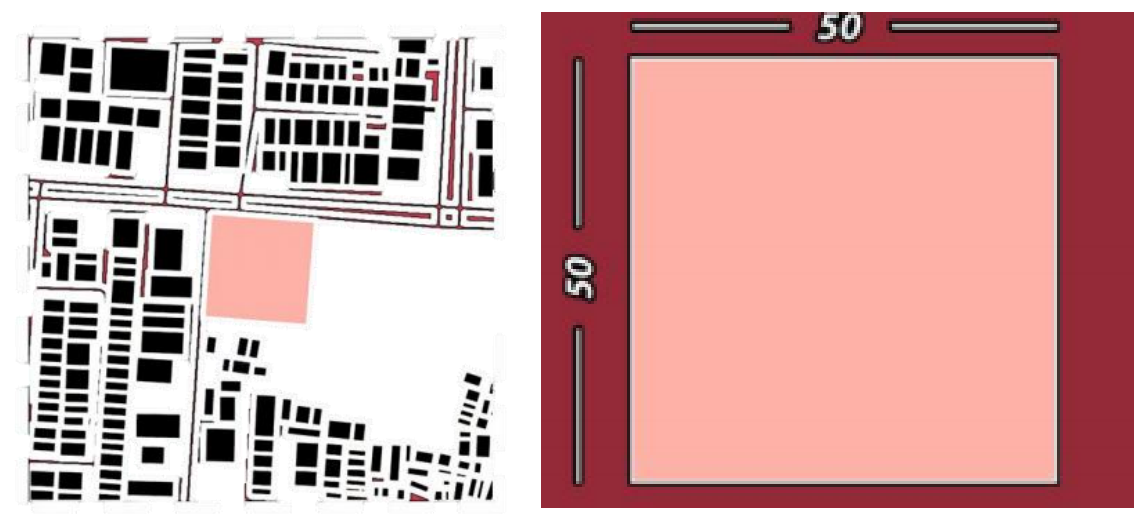

Gambar 4. Tapak

Sumber : Penulis. 2020 


\section{Denah}

Ekspresi adalah salah satu bentuk komunikasi verbal manusia dengan maksud mengungkapkan gagasan atau perasaannya. Tujuan Ruang Ekspresi yaitu sebagai wadah manusia dalam berekspresi yang dituangkan melalui seni lukis, menari, musik dan teater. Tujuan utama proyek adalah sebagai Ruang Ketiga di wilayah Pondok Kelapa, sehingga masyarakat dapat makan, bertemu, berkumpul dan beraktivitas secara leluasa.

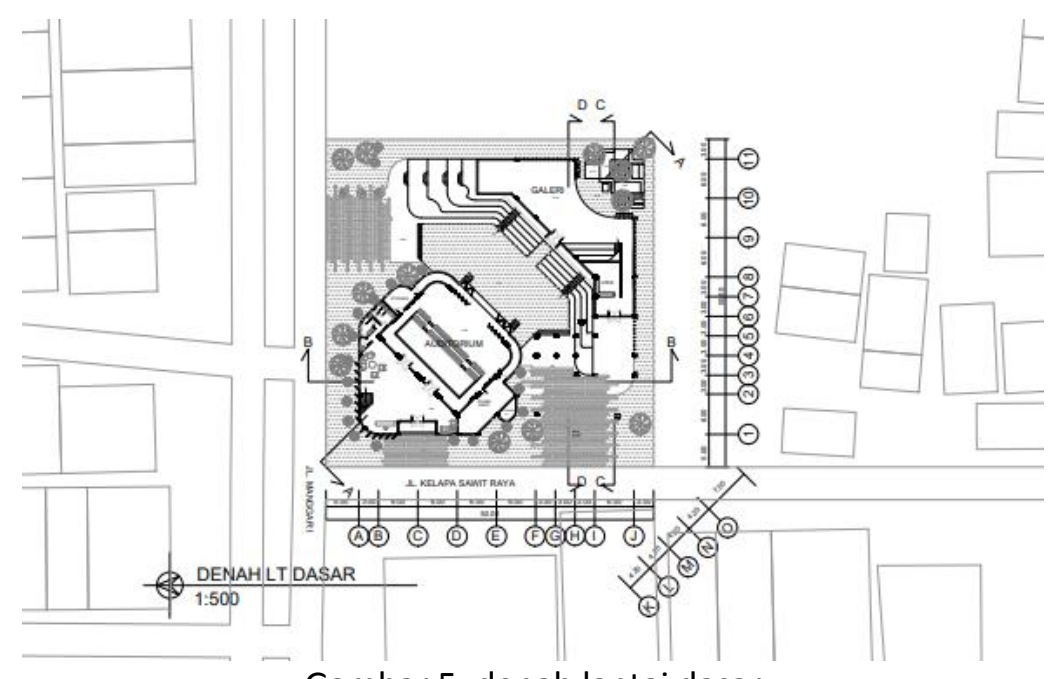

Gambar 5. denah lantai dasar

Sumber : penulis, 2020
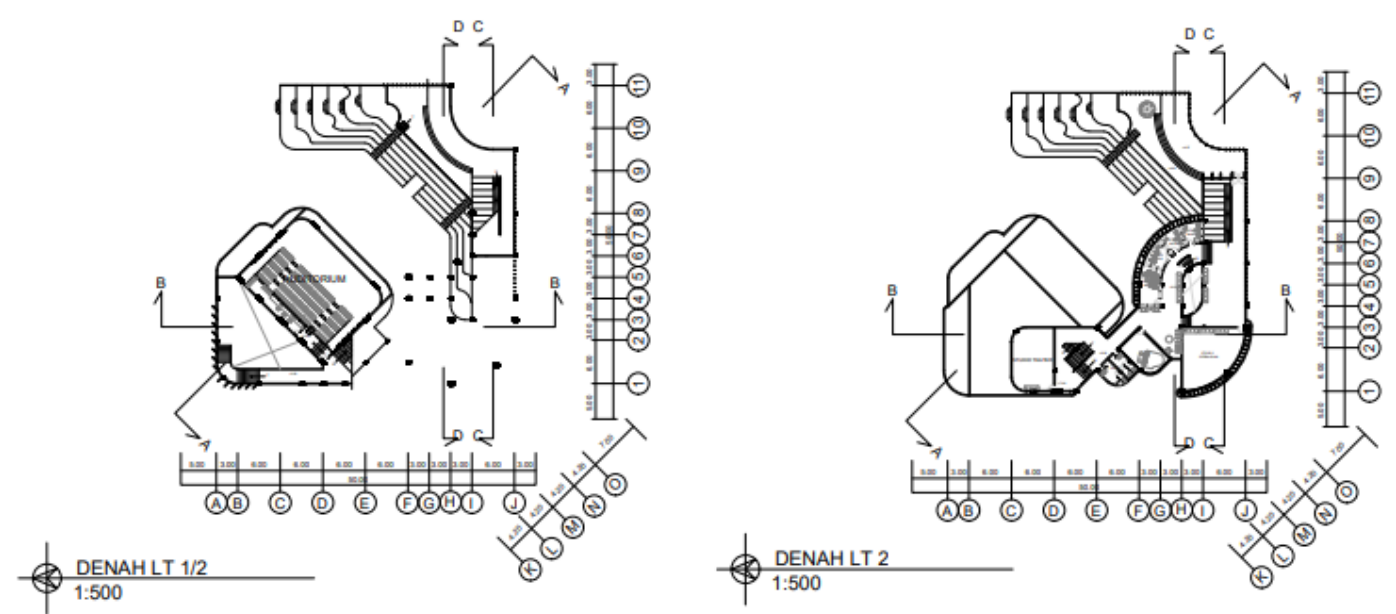

Gambar 6. Denah Lantai $1 / 2$ dan lantai 2

Sumber : Penulis, 2020 


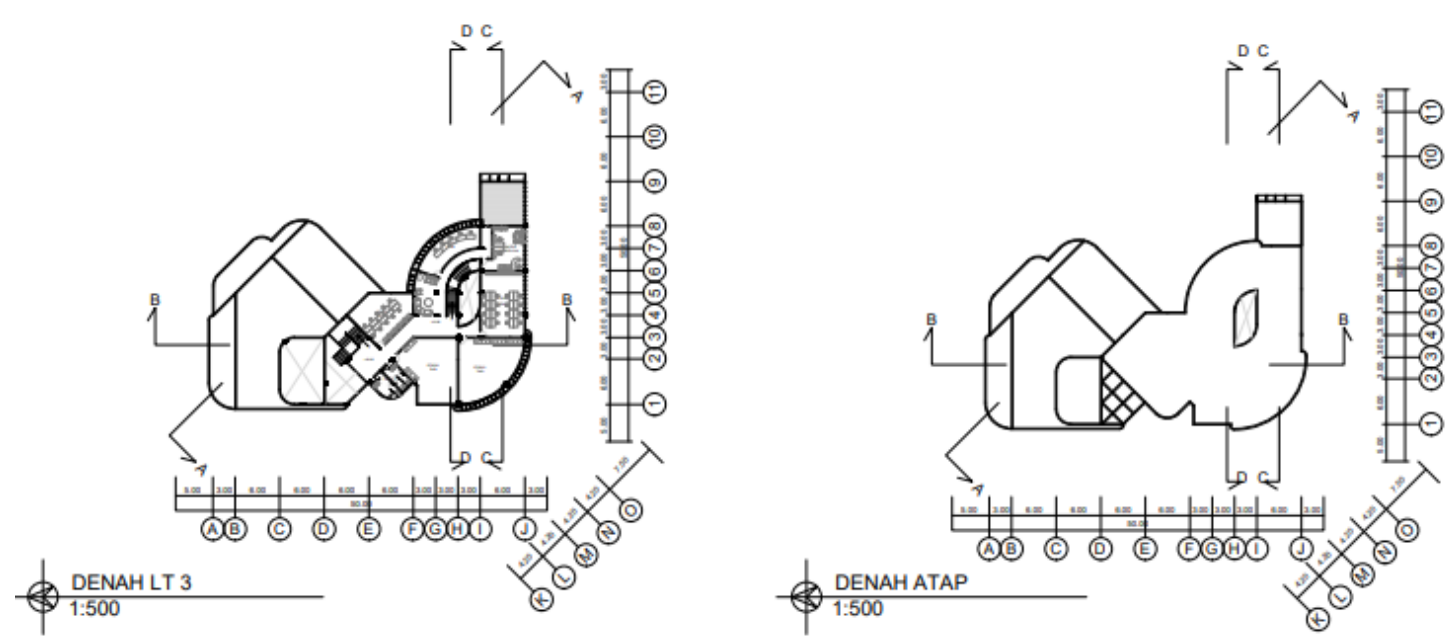

Gambar 7. Denah Lantai 3 dan atap

Sumber : Penulis, 2020

Lantai dasar adalah area untuk publik, terdapat auditorium, amphitheater, café dan galeri. Lantai dua terdapat ruang serbaguna, area studio musik dan area studio teater. Lantai tiga terdapat ruang studio menari, ruang studio seni dan ruang pengelola.

\subsubsection{Auditorium \& Amphiteater}
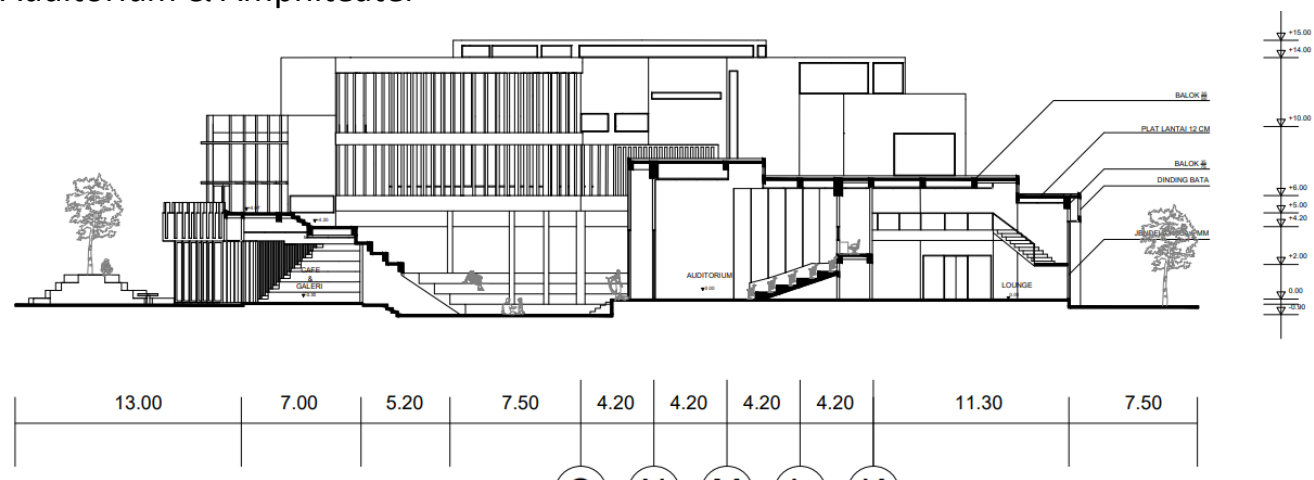

(O) M L K

Gambar 8. Potongan Auditorium dan amphitheater

Sumber : Penulis, 2020

Bagian auditorium dapat dibuka dan ditonton dari dua arah. Panggung yang dapat ditonton dari dua arah bertujuan selain untuk efisiensi ruang, pertunjukan dapat ditonton oleh banyak penonton. 


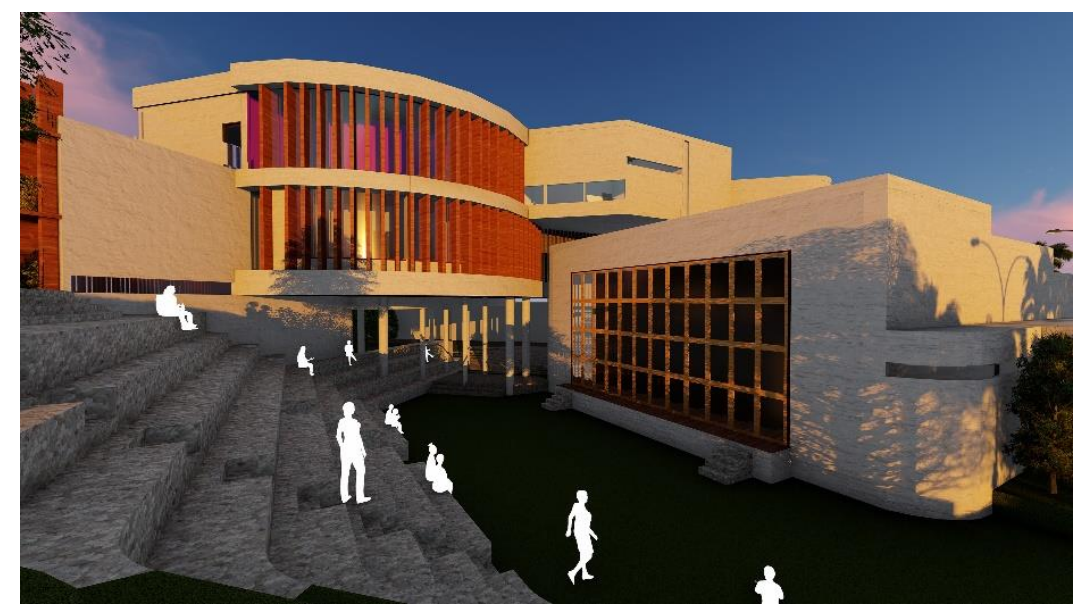

Gambar 9. Amphiteater

Sumber : Penulis, 2020

Area amphiteater merupakan area pusat aktivitas dimana area ini adalah area dimana masyarakat lebih banyak berkumpul. Lantai dasar adalah area publik yang sifatnya flexible \& indepen, dimana arti dari independen disini adalah bagaimana orang yang datang kesini memiliki kepentingan maupun kebebasan sendiri tanpa dibatasi aktivitasnya.

\section{Diskusi}

Tabel 1. Analisis Ruang Ekspresi terhadap Teori Ruang Ketiga

\section{INDIKATOR}

\section{Netral}

Ruang yang tidak terlibat oleh apapun, dari politik sampai komunitas tertentu, ruang dengan sifat netral.

\section{RUANG EKSPRESI}

Lantai dasar dari Ruang Ekspresi memang di optimalkan sebagai ruang publik, terutama bagian pusat aktivitasnya yaitu amphiteater, dimana sifatnya netral sehingga tidak memperdulikan status ekonomi dari siapapun yang datang, disini orang dapat melakukan aktivitas yang ingin dilakukan. Aktivitas utama disini adalah bertemu, mengobrol, dan bertukar informasi, jika ada sebuah acara amphiteater juga dapat berfungsi sebagai area penonton.

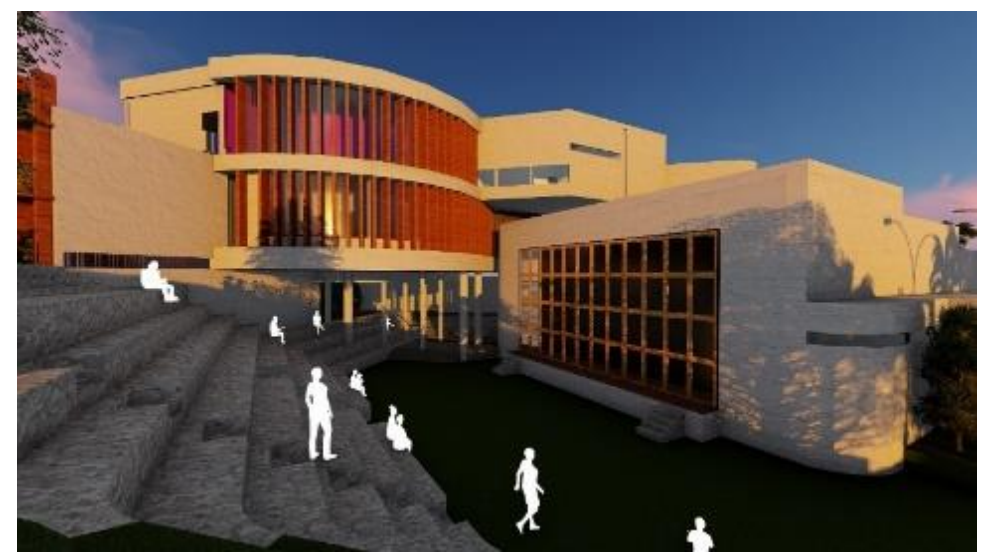

Gambar 10. Amphiteater

Sumber : Penulis, 2020 


\section{Conversation is the main activity}

Aktivitas yang paling mendominasi di ruang ketiga adalah mengobrol dan bertukar informasi.

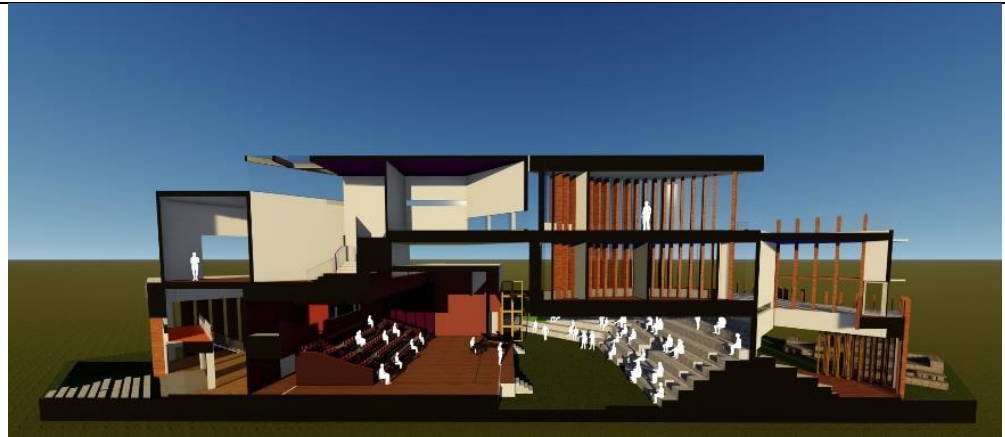

Gambar 11. Potongan perspektif auditorium dan amphitheater Sumber : Penulis, 2020

\section{Accessible}

Mudah diakses darimana saja, tidak memiliki boundaries.

Bagian lantai dasar terbuka tidak dibatasi oleh dinding-dinding pemisah

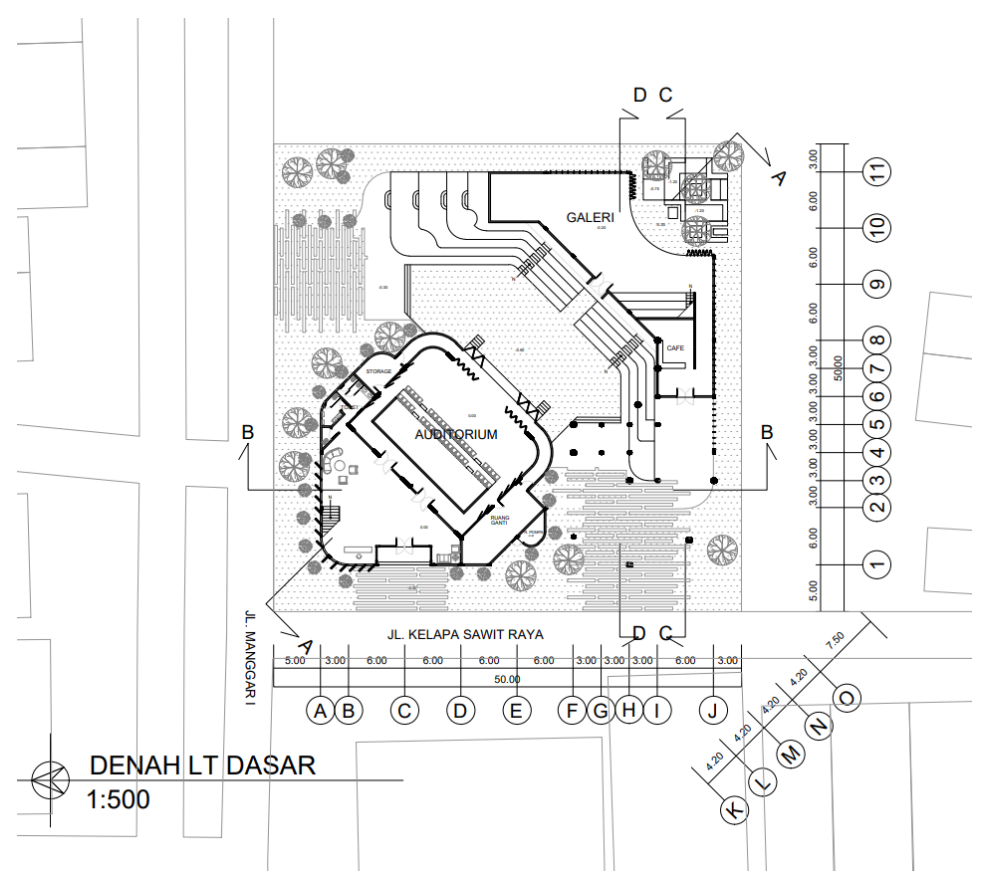

Gambar 12. Denah lantai dasar Sumber : Penulis, 2020

\section{Regulars}

Dapat digunakan oleh siapapun karena bentuk atau tampilannya yang tidak extravagant, something usual and welcoming to everybody.
Penggunaan material dan warna yang netral dan ringan bertujuan agar bentuk bangunan yang besar tidak menggangu lingkungan sekitar, yang merupakan wilayah perumahan, dan memberi kesan extravagant sehingga nantinya dapat diterima oleh semua kalangan. 


\section{Physically plain and unpretentious}

Sederhana dan dapat diterima oleh semua kalangan.

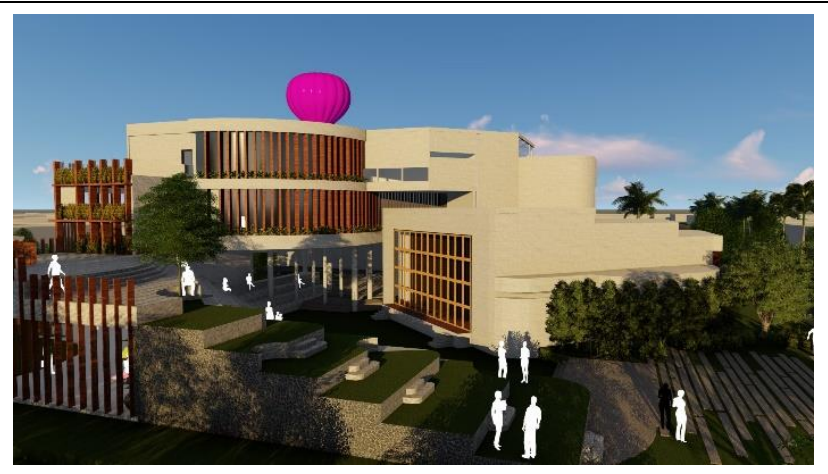

Gambar 13. Tampak timur bangunan Sumber : Penulis, 2020

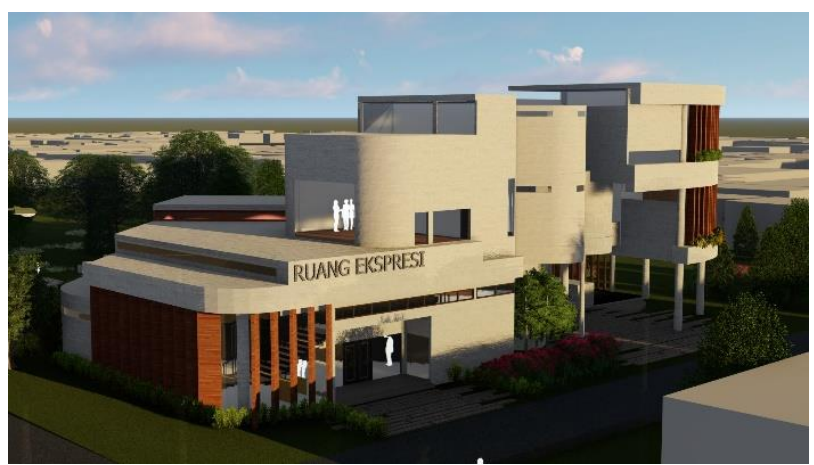

Gambar 14. Tampak barat bangunan Sumber : Penulis, 2020

\section{Dominan mood: Playful}

Ruang dimana mereka tidak dirumah tapi merasa seperti dirumah, memiliki suasana hangat dan nyaman.

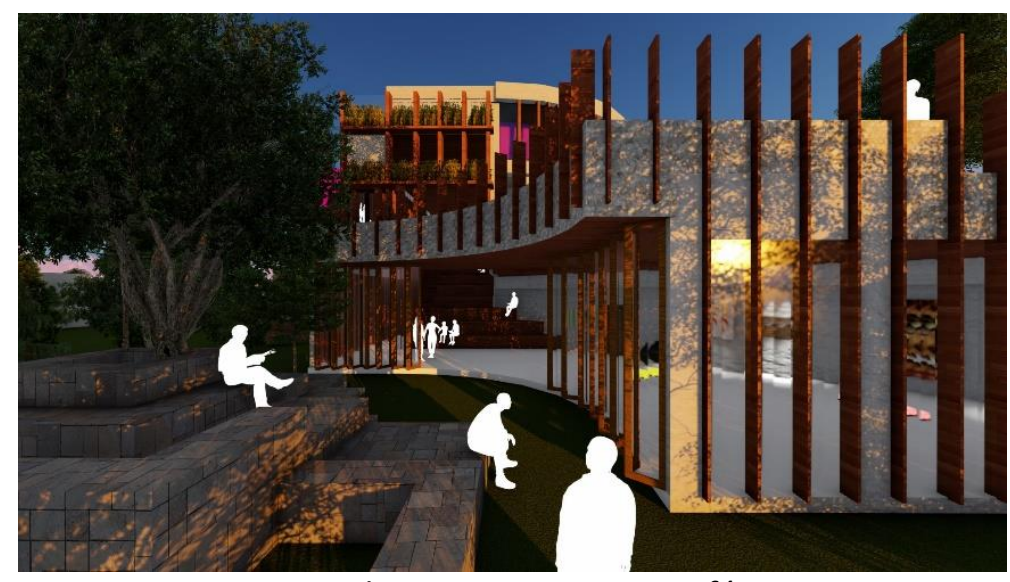

Gambar 15. Area Santai Café Sumber : Penulis, 2020 


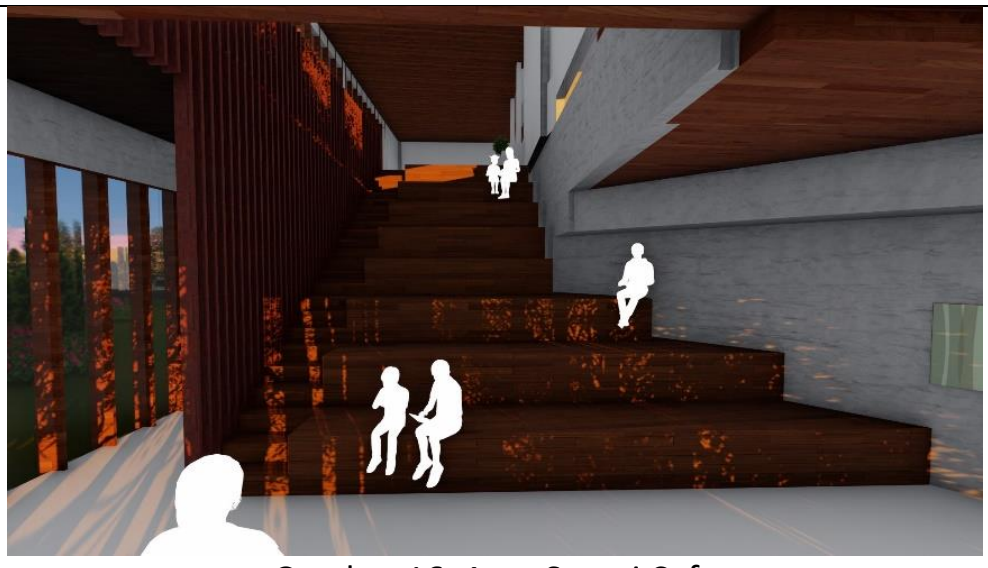

Gambar 16. Area Santai Cafe

Sumber : Penulis, 2020

Area-area diatas adalah area yang membiarkan pengunjung untuk bersantai dan melakukan aktivitas mereka secara santai dan dengan suasana yang menyenangkan. Karena area duduk yang besar sehingga tidak menghalangi aktivitas yang dilakukan seseorang di area tersebut sehingga diharapkan masyarakat merasa nyaman.

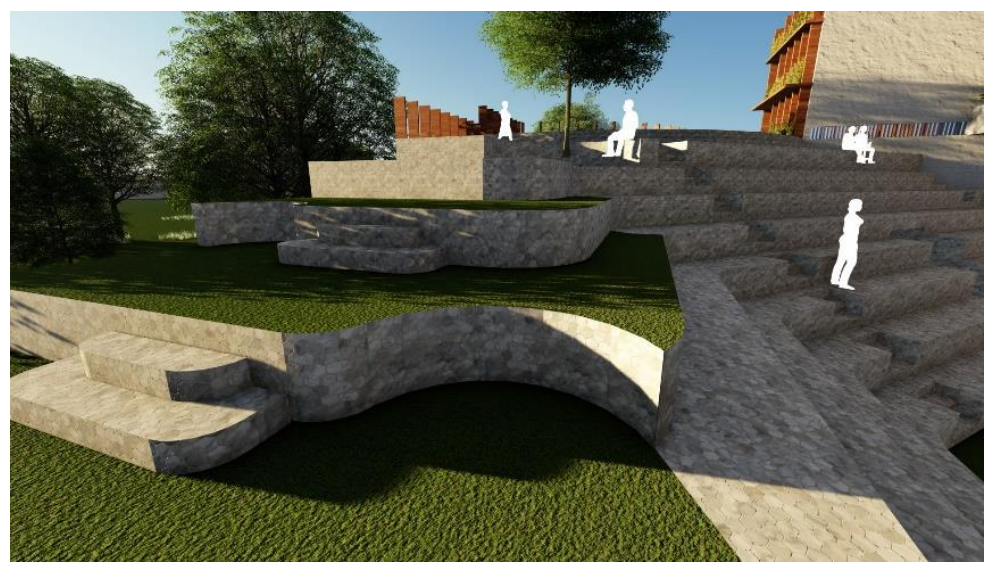

Gambar 17. Sudut duduk amphiteater Sumber : Penulis, 2020

Berdasarkan diskusi diatas maka didapatkan, bahwa Ruang Ekspresi telah memenuhi kriteria akan Ruang Ketiga yang dikemukakan oleh Ray Oldenburg(1999) dalam bukunya yang berjudul The Great Good Place, kriteria tersebut adalah bangunan bersifat netral, siapapun dapat masuk kedalam bangunan tanpa memperdulikan statusnya, bertemu dan bertukar informasi adalah aktivitas utamanya, tapak tidak memiliki boundaries sehingga mudah diakses, bentuk tampilan bangunan yang tidak berlebihan, simple, ringan dan sederhana sehingga mudah diterima oleh berbagai kalangan, suasana bangunan juga hangat juga nyaman. 


\section{KESIMPULAN DAN SARAN \\ Kesimpulan}

Ruang Ekspresi bertujuan untuk memberi wadah bagi masyarakat Pondok Kelapa berkumpul dan bertukar informasi dengan menggunakan kriteria Ruang Ketiga oleh Ray Oldenburg(The Great Good Place, 1999) sebagai acuan dalam mendisain proyek Tugas Akhir ini. Dari menyelesaikan Tugas Akhir: Ruang Ketiga ini, penulis mendapatkan simpulan tentang bagaimana menyediakan Ruang Ketiga bagi masyarakat, dimulai dari mencari rumusan masalah, analisa lokasi, analisa lingkungan, analisa tapak, menentukan program ruang dan hubungan ruang lalu data yang telah dihasilkan dapat membantu dan sangat berpengaruh dalam proses pembentukan massa, pembentukan denah dan tampak hingga penggunaan material pada bangunan, sehingga hasil akhir yang didapatkan dapat memenuhi kriteria dan kebutuhan akan Ruang Ketiga di wilayah Pondok Kelapa.

\section{Saran}

Dari penilitian yang telah dilakukan, penulis mendapat banyak ilmu baru terutama tentang pentingnya Ruang Ketiga di lingkungan manusia tinggal, maka dari itu memperbanyak Ruang Ketiga, tertutama di ibukota yang masyarakatnya mudah stress, sangat penting dan perlu. Jakarta sangat minim ruang terbuka dan Ruang Ketiga yang sifatnya netral, ruang ketiga di Jakarta didominasi oleh pusat perbelanjaan dan café, maka dari itu saya sangat berharap dimasa mendatang pemerintah memberikan kesempatan bagi arsitek perencana untuk dapat mendisain Ruang Ketiga yang bersifat publik dan netral, sehingga kualitas hidup masyarakat Jakarta juga dapat meningkat.

\section{DAFTAR PUSTAKA}

BKKBN. (2016). Kampung KB Kelurahan Pondok Kelapa. Retrieved from Kampung KB, http://kampungkb.bkkbn.go.id/profile/2981

Dolley, J., Bosman, C. (2019). Rethinking Third Places. Cheltenham: Edward Elgar Publishing Limited.

Jakarta, D. (n.d.). Data Kependudukan DKI Jakarta. Retrieved from Data Menurut Kelurahan, data.jakarta.go.id

Mackrell, J. (2008). Dance. Retrieved from Britanicca, https://www.britannica.com/art/dance

Oldenburg, R. (1999). The Great Good Place. New York: Da Capo Press.

Primala, D. A. (2017). Katarsis: Cara Mengungkap Emosi. Retrieved from Pijar Psikologi: pijarpsikologi.org

Soekadi, H. (2017). Menari Adalah Ekspresi Jiwa. Retrieved from Kompasiana, https://www.kompasiana.com/hastira/5924921b8623bdf42890ec5c/menari-adalahekspresi-jiwa

Susanto, A. (2020, January 16). Kelas Umum tentang Ruang Ketiga. 